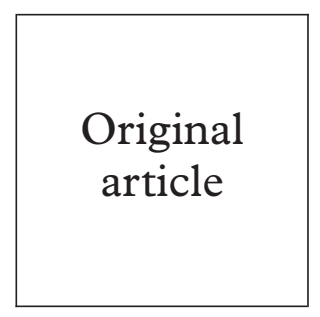

Original article

\author{
Department of \\ Preventive and Social \\ Medicine, University \\ of Otago Medical \\ School, Dunedin, New \\ Zealand \\ J E Eberhart-Phillips \\ N P Dickson \\ C Paul \\ G P Herbison
}

Westmead Millenium Institute, University of Sydney, Westmead, NSW, Australia

J Taylor

A L Cunningham

Correspondence to: Dr Jason Eberhart-Phillips, Department of Preventive and Social Medicine, PO Box 913, Dunedin, New Zealand

jeberhart@gandalf.otago.ac.nz

Accepted for publication 20 July 2001

\title{
Rising incidence and prevalence of herpes simplex type 2 infection in a cohort of 26 year old New Zealanders
}

\author{
Jason E Eberhart-Phillips, Nigel P Dickson, Charlotte Paul, G Peter Herbison, \\ Janette Taylor, Anthony L Cunningham
}

Objectives: To examine changes in the incidence and prevalence of herpes simplex type 2 (HSV-2) infection in a birth cohort of 26 year old New Zealanders in whom seroprevalence had been measured at $3.4 \%$ at age 21 .

Methods: Sera from 869 cohort members were tested using an indirect IgG enzyme linked immunoassay specific to the HSV-2 glycoprotein G. Serological results were compared with detailed sexual histories.

Results: In all, 96 participants (11\%) were seropositive for HSV-2, including at least 56 who seroconverted after their $21 \mathrm{st}$ birthday. Among those known to be seronegative at age 21, the annual seroconversion rate was 13.5 cases per 1000 per year, compared with 8.1 cases per 1000 per sexually active year before age 21 . New infections were associated with female sex and an early age of first intercourse. The average rate of partner change was lower in the cohort after age 21 , and was only modestly increased among those who acquired new HSV-2 infections between ages 21 and 26.

Conclusions: HSV-2 seroprevalence has risen sharply in this sexually active cohort, despite a reduction in the overall level of partner change. Increased rates of HSV-2 acquisition after age 21 may be due to a higher prevalence of infection in the pool of potential partners encountered during the third decade of life. Factors related to partner choice may have more influence on the risk of HSV-2 infection than the number of sexual partners alone.

(Sex Transm Inf 2001;77:353-357)

Keywords: herpes simplex virus; genital herpes; New Zealand

\section{Introduction}

Infection with herpes simplex virus type 2 (HSV-2) is the main cause of recurrent genital herpes worldwide and of initial genital herpes in most countries, including New Zealand. Numerous seroprevalence studies have shown that HSV-2 infection is common among adults from diverse populations throughout the world, despite persistent public health efforts to reduce the burden of sexually transmitted diseases (STDs) in the face of the AIDS epidemic. ${ }^{1-4}$ Most HSV-2 infections are unrecognised, and it is likely that in a majority of cases the virus is transmitted by people who are unaware that they are infected. ${ }^{5}$ Factors frequently associated with HSV-2 seropositivity include age, ${ }^{6-9}$ female sex, ${ }^{681011}$ number of sexual partners, ${ }^{6} 101213$ years of sexual activity, ${ }^{710}$ low socioeconomic status, ${ }^{6-91213}$ and a history of other STDs. ${ }^{7} 1012$

Most epidemiological studies of HSV-2 infection to date have been cross sectional in design, including one we published on the prevalence of HSV-2 antibodies in a large birth cohort of 21 year old New Zealanders from whom detailed information about sexual behaviour had been collected. ${ }^{14}$ That study found an overall seroprevalence of $3.4 \%$ in the cohort $(4.3 \%$ in females and $2.7 \%$ in males). Seropositivity tended to increase with high risk sexual behaviour, although small numbers of seropositive cases limited the power to draw conclusions. In the present study we sought to examine changes in the prevalence of HSV-2 infection in the cohort by 26 years of age, comparing the incidence of infection after age 21 with the lifetime incidence before that age. We also aimed to examine risk factors associated with both the incidence and prevalence of infection during the third decade of life.

\section{Methods}

Participants were enrolled in the Dunedin Multidisciplinary Health and Development Study, a large longitudinal investigation based on a cohort born in Dunedin, New Zealand, between 1 April 1972 and 31 March 1973. Sample members were first organised into a cohort at 3 years of age, when 1037 of 1139 eligible children were seen. ${ }^{15}$ That group was followed up every 2 years until age 15 , and again at ages 18 and 21 years. By age 26 there were 1019 known survivors of the original cohort, of whom $980(96.2 \%)$ again agreed to participate in a day long multidisciplinary assessment close to the time of their birthdays. Part of the assessment involved a computer presented questionnaire about sexual behaviour. The methods of collecting the sexual history at age 26 were almost identical to those used at age 21 , and involved a detailed account of sexual experiences, history of STDs, use of contraception, sexual attraction, and attitudes about sex. ${ }^{16}$

As was the case when cohort members turned 21 years of age, all participants in the assessment at age 26 were asked to provide a specimen of whole blood, from which serum was separated and stored at $-70^{\circ} \mathrm{C}$. It was 
explained that the blood test was to determine the prevalence in the group, and individual results were not offered. Approval for the study was received from the Otago ethics committee.

Sera were tested using an indirect IgG enzyme linked immunoassay (EIA) specific to the HSV-2 glycoprotein G (gG-2). ${ }^{17}{ }^{18}$ All sera positive by EIA for antibody to gG-2 were confirmed by western blot. One specimen that returned a negative result at age 26 had been obtained from a participant who was judged to be infected with HSV-2 at age 21 because of an equivocally positive serology. Because of uncertainty about this participant's HSV-2 status, data from this individual were excluded from the present analysis.

Serological results from the remaining participants were cross tabulated with sociodemographic characteristics, and with variables related to their reported sexual behaviour. Socioeconomic status at age 15 was based on the occupations of the participant's parents using the Elley Irving socioeconomic index for New Zealand occupations, condensing pairs from the six levels in the index into high, middle, and low categories. ${ }^{19}$ Annualised seroconversion rates before age 21 were calculated by adjusting for individual person years since age of first sexual intercourse, as reported at age 21. Annualised seroconversion rates between ages 21 and 26 were calculated by assuming 5 full years of sexual activity among those known to be sexually active by age 26 .

For each predictor variable, prevalence ratios for HSV-2 seropositivity at age 26 were calculated, together with $95 \%$ confidence intervals, using EPI-INFO version 6 statistical software. Incident cases were defined as those with positive serology at age 26 who were known to be seronegative at age 21 . Incident cases were then compared with all seronegative cases at age 26 using the same predictor variables as in the prevalence analysis. In the analysis of incident cases relative risks and 95\% confidence intervals were calculated. For both the prevalence and incidence analyses, the independent effects of key sexual behaviour variables were assessed using a logistic regression model.

\section{Results}

Of the 980 cohort members who participated in the study at age 26 years, 966 (98.6\%) answered questions about sexual behaviour. A total of 870 cohort members $(88.8 \%)$ gave a serum specimen, including four who did not answer any questions in the sexual behaviour survey. The response to the serosurvey at age 26 compares favourably with the 784 participants who gave a serum specimen at age 21 , all but 40 of whom provided a specimen again in the second study.

Of the males who answered the sexual behaviour survey at age $26,15(3.1 \%)$ reported never having intercourse with either sex, including 13 who gave a serum specimen. Only $11(2.3 \%)$ of the females had abstained from sexual intercourse with either sex, including 10 who participated in the serosurvey. The mean lifetime number of partners for the males was
15.3, compared with 11.4 for the females $(\mathrm{p}=$ $0.014)$. The mean number of partners in the previous 5 years was 7.7 for the males, compared to 4.3 for the females $(\mathrm{p}<0.0001)$.

PREVALENCE OF HSV-2 INFECTION AT AGE 26 Of the 869 specimens included in the analysis at age 26, $96(11.0 \%)$ had antibodies for HSV-2. The seropositive specimens included 22 specimens from people known to be infected at age 21 and 56 specimens from those known to be seronegative at that time. It also included 18 specimens from people whose HSV-2 status was unknown at age 21 because they had not provided specimens in the first serosurvey.

The prevalence of HSV-2 antibodies among males at age 26 was $7.1 \%$, with 32 positives obtained among 450 specimens collected. The prevalence among females was $15.3 \%$, with 64 positive specimens obtained among 419 collected ( $\mathrm{p}<0.001$ compared with males). One positive specimen was obtained from a female who denied any sexual intercourse during her lifetime.

Of the 96 infected people, 29 (30.2\%) reported a history of genital herpes at either the sexual behaviour assessment done at age 26 or at the assessment done at age 21 . This included $20(31.3 \%)$ of the infected females and nine $(28.1 \%)$ of the infected males. An additional 20 participants in the present study reported a history of genital herpes in the previous 5 years but were seronegative for HSV-2 at age 26. It was presumed that most of these cases arose from HSV-1 infection.

INCIDENCE OF HSV-2 INFECTION BETWEEN AGES 21 AND 26

There were 829 participants in the serosurvey at age 26 who were known to be seronegative at age 21 , either because they had tested negative at that time or because they were seronegative with their only test at age 26 . The 56 incident cases represent $6.8 \%$ of those known to be susceptible. These cases included $18(4.1 \%)$ of the 436 susceptible males and $38(9.7 \%)$ of the 393 susceptible females ( $\mathrm{p}<0.01)$. In all, 19 $(33.9 \%)$ of the incident cases reported a history of genital herpes during the previous 5 years. This included five $(27.8 \%)$ of the 18 male cases and $14(36.8 \%)$ of the 38 female cases.

RISK FACTORS FOR SEROPOSITIVITY AT AGE 26

Table 1 compares the 96 seropositives at age 26 with the 773 seronegatives on seven behavioural and sociodemographic variables. In general, seropositivity for HSV-2 was associated with increased number of partners, early age of first intercourse, not using a condom at last intercourse, recent history of any STD, and lower educational attainment. Low socioeconomic status of the family of origin was predictive of HSV-2 infection for females but not for males. Lower educational attainment and first intercourse at or before age 13 years were more strongly associated with seropositivity for males than for females. The likelihood of HSV-2 infection was also elevated for males 
Table 1 HSV-2 seroprevalence at age 26 by sexual behaviour* and other characteristics

\begin{tabular}{|c|c|c|c|c|c|c|}
\hline \multirow[b]{2}{*}{ Characteristic } & \multicolumn{3}{|l|}{ Males $(n=450)$} & \multicolumn{3}{|c|}{ Females $(n=419)$} \\
\hline & No (\%) positive & Prevalence ratio & $95 \% C I$ & No (\%) positive & Prevalence ratio & $95 \% C I$ \\
\hline \multicolumn{7}{|l|}{ Lifetime number of partners } \\
\hline$\geqslant 21(87 \mathrm{M}, 57 \mathrm{~F})$ & $11(12.6 \%)$ & 3.7 & $1.3-10.3$ & $15(26.3 \%)$ & 3.3 & $1.6-6.6$ \\
\hline 11 to $20(101 \mathrm{M}, 78 \mathrm{~F})$ & $7(6.6 \%)$ & 2.0 & $0.7-6.2$ & $23(29.5 \%)$ & 3.7 & $1.9-7.0$ \\
\hline 6 to $10(91 \mathrm{M}, 119 \mathrm{~F})$ & $7(7.7 \%)$ & 2.3 & $0.7-6.9$ & $13(10.9 \%)$ & 1.4 & $0.7-2.9$ \\
\hline 1 to $5(146 \mathrm{M}, 150 \mathrm{~F})$ & $5(3.4 \%)$ & 1.0 & & $12(8.0 \%)$ & 1.0 & \\
\hline \multicolumn{7}{|l|}{ Number of partners in past 5 years } \\
\hline$\geqslant 6(171 \mathrm{M}, 92 \mathrm{~F})$ & $18(10.5 \%)$ & 2.3 & $0.8-6.6$ & $25(27.2 \%)$ & 3.6 & $1.8-7.4$ \\
\hline 2 to $5(170 \mathrm{M}, 183 \mathrm{~F})$ & $8(4.7 \%)$ & 1.0 & $0.3-3.3$ & $29(15.8 \%)$ & 2.3 & $1.1-4.7$ \\
\hline 0 to $1(88 \mathrm{M}, 131 \mathrm{~F})$ & $4(4.5 \%)$ & 1.0 & & $9(6.9 \%)$ & 1.0 & \\
\hline \multicolumn{7}{|l|}{ Age at first intercourse } \\
\hline$\leqslant 13$ years $(29 \mathrm{M}, 25 \mathrm{~F})$ & $6(20.7 \%)$ & 4.7 & $1.9-11.8$ & $8(32.0 \%)$ & 2.7 & $1.4-5.5$ \\
\hline $14-16$ years $(157 \mathrm{M}, 188 \mathrm{~F})$ & $15(9.6 \%)$ & 2.2 & $1.0-4.6$ & $32(17.0 \%)$ & 1.5 & $0.9-2.4$ \\
\hline$>16$ years $(249 \mathrm{M}, 197 \mathrm{~F})$ & $11(4.4 \%)$ & 1.0 & & $23(11.7 \%)$ & 1.0 & \\
\hline \multicolumn{7}{|l|}{ Condom at last intercourse? } \\
\hline No $(281 \mathrm{M}, 308 \mathrm{~F})$ & $24(8.5 \%)$ & 2.1 & $0.9-5.1$ & $53(17.2 \%)$ & 1.7 & $0.9-3.2$ \\
\hline Yes $(150 \mathrm{M}, 99 \mathrm{~F})$ & $6(4.0 \%)$ & 1.0 & & $10(10.0 \%)$ & 1.0 & \\
\hline \multicolumn{7}{|l|}{ STD in past 5 years? } \\
\hline Yes $(75 \mathrm{M}, 65 \mathrm{~F})$ & $10(13.3 \%)$ & 2.6 & $1.2-5.4$ & $24(36.9 \%)$ & 3.3 & $2.1-5.0$ \\
\hline No $(348 \mathrm{M}, 343 \mathrm{~F})$ & $18(5.2 \%)$ & 1.0 & & $39(11.4 \%)$ & 1.0 & \\
\hline \multicolumn{7}{|l|}{ Socioeconomic status at 15 years } \\
\hline Low $(34 \mathrm{M}, 43 \mathrm{~F})$ & $2(5.9 \%)$ & 1.0 & $0.2-4.7$ & $11(25.6 \%)$ & 3.2 & $1.5-6.8$ \\
\hline Middle $(216 \mathrm{M}, 187 \mathrm{~F})$ & $15(6.9 \%)$ & 1.2 & $0.5-2.8$ & $31(16.6 \%)$ & 2.1 & $1.1-3.9$ \\
\hline $\operatorname{High}(141 \mathrm{M}, 136 \mathrm{~F})$ & $8(5.7 \%)$ & 1.0 & & $11(8.1 \%)$ & 1.0 & \\
\hline \multicolumn{7}{|l|}{ Highest school qualification } \\
\hline High school or less $(161 \mathrm{M}, 147 \mathrm{~F})$ & $18(11.2 \%)$ & 10.0 & $1.4-73.3$ & $28(19.0 \%)$ & 2.6 & $1.3-5.6$ \\
\hline Post-secondary, not university (195 M, $158 \mathrm{~F})$ & $12(6.2 \%)$ & 5.5 & $0.7-41.5$ & $27(17.1 \%)$ & 2.4 & $1.1-5.0$ \\
\hline University $(89 \mathrm{M}, 111 \mathrm{~F})$ & $1(1.1 \%)$ & 1.0 & & $8(7.2 \%)$ & 1.0 & \\
\hline
\end{tabular}

*Analysis of sexual behaviour variables excludes 13 males and 10 females with no sexual partners in their lifetimes.

whose first sexual partner was aged 13 years or younger (prevalence ratio $=3.4,95 \% \mathrm{CI}=$ 1.3-8.6). No such association was seen for females. When controlling for the number of partners in a lifetime, the association between HSV-2 infection at age 26 and an early age of first intercourse remained for the males but lost statistical significance for the females.

Variables that were not associated with HSV-2 seropositivity for either sex included number of partners in the previous 12 months, frequency of condom use in the previous 12 months, number of STDs in the previous 5 years, sexual contact with the same sex, place of residence, and attitude towards "one night stands." Similarly, no associations were found for a group of variables dealing with a participant's current relationship, including the length of the relationship, the age of the partner, and whether the participant had other partners during the relationship. As a group, females in relationships were more likely than males to report that their current partner was more sexually experienced than they were (33\% of females compared with $21 \%$ of males, $\mathrm{p}<0.001)$.

RISK FACTORS FOR INCIDENCE BETWEEN AGES 21 AND 26

Table 2 compares the 56 incident cases occurring between ages 21 and 26 with the 773 seronegatives on the same seven variables. The observed associations followed the general patterns seen with prevalence, except that lifetime number of partners and the sociodemographic variables do not predict HSV-2 incidence reliably. As expected, number of partners in the past 5 years and recent history of any STD are associated with incidence. Curiously, a very early age of first intercourse is an even stronger predictor of HSV-2 incidence between ages 21 and 26 than it is of prevalence at age 26. Again, the risk of infection for males only was also elevated if their first partner was 13 years or younger (relative risk $=4.9,95 \% \mathrm{CI}=$ 1.6-55.2). The same variables that showed no relation to seroprevalence at age 26 had no association with incidence of HSV-2 between ages 21 and 26 years. When controlling for number of partners in the past 5 years, the association of HSV-2 incidence with an early age of first intercourse remained strong for both males and females.

DIFFERENCES IN RISK OF HSV-2 ACQUISITION BEFORE AND AFTER AGE 21

The annualised seroconversion rate in the cohort before age 21 was only 8.1 cases per 1000 per year, after adjusting for person years since first sexual intercourse. The rate was 6.9 cases per 1000 per year for males and 9.4 cases per 1000 per year for females. By contrast, the 56 new cases arising in the cohort between ages 21 and 26 years yielded an annualised seroconversion rate of 13.5 cases per 1000 per year during that time. This rate was 8.3 cases per 1000 per year for males and 19.3 cases per 1000 per year for females.

The mean reported number of sexual partners among seropositive participants at age 21 was 3.2 per year since the start of sexual activity (4.3 for males, 2.5 for females). This was substantially higher than the rate of 1.6 partners per year reported by the seronegative participants at that age (1.9 for males, 1.3 for females) or the rate of 1.7 partners per year in the cohort overall. By contrast, those who acquired the infection after age 21 reported an average of just 1.6 partners per year during the 5 year period before age 26 (2.3 for males, 1.2 for females). This was only slightly greater than the rate of 1.20 partners per year reported during that time by those who remained seronegative ( 1.5 for males, 0.8 for females) or the rate of 1.23 partners per year in the cohort overall. 
Table 2 HSV-2 incidence between ages 21 and 26 by sexual behaviour* (reported at age 26) and other characteristics

\begin{tabular}{|c|c|c|c|c|c|c|}
\hline \multirow[b]{2}{*}{ Characteristic } & \multicolumn{3}{|l|}{ Males $(n=436)$} & \multicolumn{3}{|l|}{ Females $(n=393)$} \\
\hline & No (\%) positive & Relative risk & $95 \% C I$ & No (\%) positive & Relative risk & $95 \% C I$ \\
\hline \multicolumn{7}{|l|}{ Lifetime number of partners } \\
\hline$\geqslant 21(80 \mathrm{M}, 49 \mathrm{~F})$ & $4(5.0 \%)$ & 2.4 & $0.6-10.5$ & $7(14.3 \%)$ & 2.1 & $0.9-5.3$ \\
\hline 11 to $20(100 \mathrm{M}, 71 \mathrm{~F})$ & $6(6.0 \%)$ & 2.9 & $0.7-11.3$ & $16(22.5 \%)$ & 3.3 & $1.6-7.0$ \\
\hline 6 to $10(88 \mathrm{M}, 111 \mathrm{~F})$ & $4(4.5 \%)$ & 2.2 & $0.5-9.5$ & $5(4.5 \%)$ & 0.7 & $0.2-1.9$ \\
\hline 1 to $5(144 \mathrm{M}, 148 \mathrm{~F})$ & $3(2.1 \%)$ & 1.0 & & $10(6.8 \%)$ & 1.0 & \\
\hline \multicolumn{7}{|l|}{ Number of partners in past 5 years } \\
\hline$\geqslant 6(163 \mathrm{M}, 82 \mathrm{~F})$ & $10(6.1 \%)$ & 5.2 & $0.7-40.1$ & $15(18.3 \%)$ & 3.0 & $1.3-6.7$ \\
\hline 2 to $5(168 \mathrm{M}, 169 \mathrm{~F})$ & $6(3.6 \%)$ & 3.0 & $0.4-24.8$ & $15(8.9 \%)$ & 1.4 & $0.6-3.3$ \\
\hline 0 to $1(85 \mathrm{M}, 130 \mathrm{~F})$ & $1(1.2 \%)$ & 1.0 & & $8(6.2 \%)$ & 1.0 & \\
\hline \multicolumn{7}{|l|}{ Age at first intercourse } \\
\hline$\leqslant 13$ years $(26 \mathrm{M}, 23 \mathrm{~F})$ & $3(11.6 \%)$ & 5.6 & $1.4-22.1$ & $6(26.1 \%)$ & 4.1 & $1.7-9.7$ \\
\hline $14-16$ years $(152 \mathrm{M}, 176 \mathrm{~F})$ & $10(6.6 \%)$ & 3.0 & $1.1-9.2$ & $20(11.4 \%)$ & 1.8 & $0.9-3.5$ \\
\hline$>16$ years $(243 \mathrm{M}, 186 \mathrm{~F})$ & $5(2.1 \%)$ & 1.0 & & $12(6.5 \%)$ & 1.0 & \\
\hline \multicolumn{7}{|l|}{ Condom at last intercourse? } \\
\hline No $(270 \mathrm{M}, 288 \mathrm{~F})$ & $13(4.8 \%)$ & 1.8 & $0.6-5.4$ & $33(11.5 \%)$ & 2.2 & $0.9-5.4$ \\
\hline Yes $(148 \mathrm{M}, 94 \mathrm{~F})$ & $4(2.7 \%)$ & 1.0 & & $5(5.3 \%)$ & 1.0 & \\
\hline \multicolumn{7}{|l|}{ STD in past 5 years? } \\
\hline Yes $(72 \mathrm{M}, 58 \mathrm{~F})$ & $7(9.7 \%)$ & 4.1 & $1.5-11.0$ & $17(29.3 \%)$ & 4.5 & $2.6-8.1$ \\
\hline No $(338 \mathrm{M}, 325 \mathrm{~F})$ & $8(2.4 \%)$ & 1.0 & & $21(6.5 \%)$ & 1.0 & \\
\hline \multicolumn{7}{|l|}{ Socioeconomic status at 15 years } \\
\hline Low $(33 \mathrm{M}, 37 \mathrm{~F})$ & $1(3.0 \%)$ & 1.4 & $0.2-12.8$ & $5(13.5 \%)$ & 2.6 & $0.9-7.6$ \\
\hline Middle $(212 \mathrm{M}, 176 \mathrm{~F})$ & $11(5.2 \%)$ & 2.4 & $0.7-8.3$ & $20(11.4 \%)$ & 2.1 & $0.9-4.9$ \\
\hline High $(136 \mathrm{M}, 132 \mathrm{~F})$ & $3(2.2 \%)$ & 1.0 & & $7(5.3 \%)$ & 1.0 & \\
\hline \multicolumn{7}{|l|}{ Highest school qualification } \\
\hline High school or less $(154 \mathrm{M}, 132 \mathrm{~F})$ & $11(7.1 \%)$ & 6.4 & $0.8-48.4$ & $13(9.8 \%)$ & 1.8 & $0.7-4.6$ \\
\hline Post-secondary, not university $(188 \mathrm{M}, 150 \mathrm{~F})$ & $5(2.7 \%)$ & 2.4 & $0.3-20.0$ & $19(12.7 \%)$ & 2.3 & $1.0-5.6$ \\
\hline University $(89 \mathrm{M}, 109 \mathrm{~F})$ & $1(1.1 \%)$ & 1.0 & & $6(5.5 \%)$ & 1.0 & \\
\hline
\end{tabular}

^Analysis of sexual behaviour variables excludes 13 males and 9 females with no sexual partners in their lifetimes.

\section{Discussion}

HSV-2 infection in this large, population based cohort of young New Zealanders has increased substantially between ages 21 and 26 years to an overall level of $11 \%$. The rate of HSV-2 acquisition was substantially higher after age 21 than before. The extremely low dropout rate in this cohort over time and the high level of participation in the present serosurvey have afforded a high degree of precision in measuring the true level of infection in this population. Even in the unlikely event that all living members of the original cohort who were not included in the study were not infected at age 26 , the overall seroprevalence would be no lower than $9.4 \%$, roughly three times as high as it was 5 years earlier.

The sharp increase in HSV-2 seroprevalence observed between ages 21 and 26 brings the level of infection in this New Zealand cohort within range of that seen among young adults in other general population samples. ${ }^{368}$ The acceleration in incidence seen during the first half of the third decade of life in this cohort mirrors that seen in the age specific analyses of cross sectional studies performed elsewhere and in the few cohorts that have been followed prospectively. ${ }^{20}{ }^{21}$ The finding that only about one third of infections in both males and females were recognised clinically is consistent with other studies, ${ }^{11}{ }^{22}$ and demonstrates the public health challenge in controlling HSV-2 transmission, as asymptomatic people like those in this study shed the virus and are infectious to others.

As we found in this cohort at age 21, infection with HSV-2 tended to be associated with high risk sexual behaviour, as measured by numbers of partners and other parameters. But the higher rates of HSV-2 acquisition that we observed between ages 21 and 26 cannot be explained by increased numbers of new partners during that time. A much higher level of partner change was associated with HSV-2 acquisition before age 21 than was seen subsequently. In fact, people who seroconverted after age 21 reported a lower level of partner change than was seen in the cohort as a whole before age 21 . Their level of partner change after age 21 was only slightly greater than that seen in people who remained seronegative to age 26 .

The relatively high incidence of $\mathrm{HSV}-2$ infection seen after age 21 despite a much lower rate of partner change suggests that during the third decade of life partner selection assumes a greater role in determining HSV-2 risk than simple numbers of partners. It is also plausible that before age 21 the prevalence of HSV-2 infection in the pool of one's potential partners is lower than it is later in life. Only those with exceptionally high numbers of partners before age 21 are likely to encounter the virus. By contrast, after age 21 the prevalence of HSV-2 in the pool of potential partners has increased, and the higher prevalence of infection among partners drives the observed increase in incidence.

Remarkably, a very early age of first intercourse has remained an indicator of ongoing risk of HSV-2 acquisition after age 21 years, as has a young age of a first partner, at least for males. These factors cannot be acting directly on risk, as they relate to behaviours that predate the occurrence of infection by several years. Instead, they must be acting through more proximal factors that influence risk of infection during the third decade of life, such as choice of partners. It is likely that early age of first intercourse is a marker for a group of risky behaviours in young adulthood, ${ }^{23}$ especially for males, which in turn may be associated with selection of partners at greater risk of HSV-2 infection. Females with very early sexual experience may be more vulnerable later in life to exploitative sexual behaviour, which may increase their contact with infected partners. 
A striking finding of this study was the widening difference in HSV-2 infection between males and females. Females were roughly twice as likely to be infected at age 26 and twice as likely to acquire the infection between ages 21 and 26, compared to males. When controlling for the higher number of partners reported by males, the risk of infection in females was actually about three times that seen in males. Often the females in the lowest risk categories for the behavioural variables in the study had higher levels of infection than the males in the highest risk categories.

Such a disparity between the sexes has been observed consistently in other general population serosurveys. ${ }^{6810}$ It is also evident in the routinely collected surveillance data for clinical cases of genital herpes in this age group, as reported by New Zealand's STD clinics. ${ }^{24}$ The preponderance of cases in females may be due to greater efficiency in viral transmission from men to women than from women to men. ${ }^{25} \mathrm{It}$ may also reflect differences in partner selection between men and women. As a group, the females in this cohort were much more likely than the males to report that their current partner was more sexually experienced than they were. This suggests that, as a group, young women are more likely to be exposed to the virus from their partners than are men of the same age.

In our previous study we accounted for the relatively low prevalence of $\mathrm{HSV}-2$ infection in this sexually active cohort at age 21 by suggesting that there was a low critical mass of HSV-2 carriers in the cohort's pool of potential partners. Now, at age 26, it appears that this critical mass has grown, and is driving the increases in HSV-2 incidence that we have observed, despite a substantial reduction in the level of partner change in the cohort since age 21 . Rates of partner change are only slightly greater than average in those who have seroconverted since age 21, suggesting that choice of partners may have a greater role than numbers of partners in determining HSV-2 risk during the third decade of life. A very early age of first intercourse may also act through partner selection to increase HSV-2 risk between ages 21 and 26 .

Source of funding: Health Research Council of New Zealand. Conflict of interest: None

Contributors: JEEP, study idea, data analysis and interpretContributors: JEEP, study idea, data analysis and interpret-
ation, report writing; NPD, study idea, design of sexual behavition, report writing; NPD, study idea, design of sexual behavCP, study idea, interpretation of data, manuscript review; GPH, $\mathrm{CP}$, study idea, interpretation of data, manuscript review; GPH,
statistical advice, assistance with data analysis and interpretstatistical advice, assistance with data analysis and interpret-
ation, manuscript review; JT, handling of specimens, serum assays, manuscript review; ALC, supervision of laboratory tests, assays, manuscript review; ALC, supervision
interpretation of data, manuscript review.
1 Slomka M J. Seroepidemiology and control of genital lomka $M$ J. Seroepidemiology and control of genital herpes: the value of type specific an

plex virus. $C D R$ Rev 1996;6:R41-5.
2 Nahmias AJ, Lee FK, Beckman-Nahmias S. Seroepidemiological and -sociological patterns of herpes simplex virus infection in the world. Scand 7 Infect Dis 1990;69(suppl):19-36.

3 Fleming DT, McQuillan GM, Johnson RE, et al. Herpes simplex virus type 2 in the United States, 1976 to 1994 . $N$ Engl f Med 1997;337:1105-11.

4 Cunningham AL, Mindel A, Dwyer DE. Global epidemiology of sexually transmitted diseases. In: Stanberry LR, Bernstein DI, eds. Sexaully transmitted diseases: vaccines, prevention and control. San Diego: Academic Press, 2000

5 Brugha R, Keersmaekers K, Renton A, et al. Genital herpes infection: a review. Int $\mathcal{F}$ Epidemiol 1997;26:698-709.

6 Siegel D, Golden E, Washington AE, et al. Prevalence and correlates of herpes simplex infections: the populationbased AIDS in multiethnic neighborhoods study. $7 A M A$ 1992;268:1702-8

7 Breinig MK, Kingsley LA, Armstrong JA, et al. Epidemiology of genital herpes in Pittsburgh: serologic, sexual, and racial correlates of apparent and inapparent herpes simplex infections. F Infect Dis 1990;162:299-305.

8 Oliver L, Wald A, Kim M, et al. Seroprevalence of herpes simplex virus infections in a family medicine clinic. Arch Fam Med 1995;4:228-32.

9 Cunningham AL, Lee FK, Ho DWT, et al. Herpes simplex virus type 2 antibody in patients attending antenatal or STD clinics. Med $\mathcal{F}$ Aust 1993;158:525-8.

10 Cowan FM, Johnson AM, Ashley R, et al. Antibody to herpes simplex virus type 2 as serological marker of sexual lifestyle in populations. BMf 1994;309:1325-9.

11 Langenberg AGM, Corey LC, Ashley RL, et al. A prospective study of new infections with herpes simplex virus type 1 and type 2. N Engl F Med 1999;341:1432-8.

12 Wald A, Koutsky L, Ashley RL, et al. Genital herpes in a primary care clinic: demographic and sexual correlates of herpes simplex type 2 infections. Sex Transm Dis 1997;24:14955 .

13 Stavraky KM, Rawls WE, Chiavetta J, et al. Sexual and socioeconomic factors affecting the risk of past infections with herpes simplex virus type 2. Am F Epidemiol 1983;118: 109-21.

14 Eberhart-Phillips J, Dickson NP, Paul C, et al. Herpes simplex type 2 infection in a cohort aged 21 years. Sex Transm Infect 1998;74:216-8.

15 Silva PA, Stanton WR, eds. From child to adult: the Dunedin multidisciplinary health and development study. Auckland: Oxford University Press, 1996.

16 Dickson N, Paul C, Herbison P, et al. The lifetime occurrence of sexually transmitted diseases among a cohort aged 21. NZ Med f 1996;109:308-12.

17 Ho DW, Field PR, Sjogren-Jansson E, et al. Indirect ELISA for the detection of HSV-2 specific IgG and IgM antibodes with glycoprotein G (gG-2) F Virol Meth 1992;36:249-

18 Ho DW, Field PR, Irving WL, et al. Detection of immunoglobulin $M$ antibodies to glycoprotein G-2 by western blot (immunoblot) for diagnosis of initial herpes
simplex virus type 2 genital infections. 7 Clin Microbiol simplex virus type 2

9 1993;31:3157-64. Zealanders. NZ F Educ Stud 1976;11:25-30.

20 Christenson B, Bottiger M, Svensson A, et al. A 15-year surveillance study of antibodies to herpes simplex virus types 1 and 2 in a cohort of young girls. F Infect 1992;25:147-54.

21 Corey L, Wald A. Genital herpes. In: Holmes KK, Mardh PA, Sparling PF, et al, eds. Sexually transmitted diseases. 3rd ed. New York: McGraw-Hill, 1999.

22 Koutsky LA, Ashley RL, Holmes KK, et al. The frequency of unrecognized type 2 herpes simplex virus infection among women. Implications for the control of genital herpes. Sex Transm Dis 1990;17:90-4

23 Paul C, Fitzjohn J, Herbison P, et al. The determinants of sexual intercourse before age 16. F Adoles Health 2000;27: $136-47$

24 Turley M, McNicholas A, Nesdale A, et al. STI surveillance: annual report fanuary -December 1999. Wellington: Institute of Environmental Science and Research, 2000.

25 Mertz GJ, Benedetti J, Ashley R, et al. Risk factors for the sexual transmission of genital herpes. Ann Intern Med 1992;116:197-202. 